\title{
Adhesion Stress Prediction in Polymer Concrete Using Fuzzy Logic Model
}

\author{
ADINA RUSU ${ }^{1}$, LILIANA BEJAN ${ }^{1}$, MARINELA BARBUTA ${ }^{2}$, VIOREL-PUIU PAUN ${ }^{3 *}$ \\ ${ }^{1}$ Tehnical University "Gh.Asachi" Jassy, Faculty of Machine Manufacturing and Industrial Management, Theoretical Mechanics Department, Iasi, \\ Romania \\ ${ }^{2}$ Tehnical University "Gh.Asachi" Jassy, Faculty of Civil Engineering and Building Services, Iasi, Romania \\ ${ }^{3}$ University Politehnica of Bucharest, Faculty of Applied Sciences, Physics Department, Bucharest,Romania
}

In recent years, in many areas of civil engineering applications, fuzzy logic models have been used. The aim of this paper is to develop a fuzzy logic model to predict the adhesion stress in polymer concrete. Availability of experimental data was required to develop the relationship between the mixture variables of polymer concrete and its measured properties. The basic parameters considered in this study were epoxy resin, silica fume, aggregate sort I and aggregate sort II dosage. Using Mamdani fuzzy model, with the said parameters, we effectively predicted the adhesion stress in polymer concrete accurately by taking into account the parameters of the problem. In these circumstances, data can be acquired in a short period of time without wasting material, with decreased design cost, all this without attempting experiments and thus saving time. This study showed that the model used has a good prediction and generalization capacity with acceptable errors.

Keywords: Fuzzy logic; Polymer concrete; Adhesion stresss; Mechanical properties; Modelization.

In construction industry, new materials have been developed during the last decades. Polymer concrete is an important type of concrete, used especially in precast-elements, waterproofing and corrosion protection layers, repairs in bridges and structures, etc. [1-3].

Polymer concrete presents some advantages in comparison with ordinary cement concrete such as higher mechanical strengths, good adherence and increased durability due to higher corrosion resistance and lower permeability. Different types of resins can be used in the mix of polymer concrete, such as: epoxy resin, polyester resin, furan resin, epoxy polyurethane acryl, etc. $[4,5]$.

New research in polymer concrete domain had studied the possibilities of introducing wastes as component on the mix. Different types of wastes such as: fly ash, silica fume, marble powder, slag, glass, tires, chopped plastic bottles, etc. had been used as addition to the mix or as replacement of aggregates [6-10].

In recent years, the analytical methods using artificial intelligence such as fuzzy logic have increasingly been applied to predict mechanical characteristics of concrete. The training process of the artificial intelligence systems based on the outcome of experiments represents the ground for developing artificial intelligence systems used to foresee material behavior. Thus, with relevant information from experimental results regarding the material behavior, the trained artificial intelligence systems will be able to forecast material behaviour [11].

In this paper we purposely research a methodology using a fuzzy inference system (FIS) to predict the adhesion stress (AS) of polymer concrete (PC), an important property in repair and consolidation works of concrete structures.

\section{Theoretical part}

Fuzzy Logic

The "fuzzy set" concept was introduced by Zadeh [12] who pioneered the development of the fuzzy logic. In human thinking, the key elements are considered the levels of fuzzy sets through linguistic words but not the numbers. Hence, linguistic variables are introduced as parameter descriptions in a natural and logical linguistic statements or propositions.

The fuzzy logic (FL) concept helps solving problems in which the source of imprecision is the absence of sharply defined criteria [13]. Uncertainty does not stand for chance. Uncertainty is neither a probabilistic or stochastic variation based numerical data. Fuzzy logic theory comes up with deep calculation in order to settle such information linguistically. With linguistic labels activated by membership functions, fuzzy approach runs numerical computation. Zadeh developed linguistic variables as variables whose values are sentences in a natural or artificial language. Although fuzzy logic was advanced by Zadeh in 1965, fuzzy concepts and systems came in focus only in 1975 by Mamdani and Assilian [14] with a real control application.

*email:viorel_paun2006@yahoo.com; viorel.paun@physics.pub.ro 
The ability of partial belongings of any object to different subsets of the whole set instead of belonging to a fully single set stands as the ground mechanism of the FL. Partial belonging to set can be numerically described by a membership function allocating values between 0 and 1 [15].

\section{Fuzzy Logic Inference System}

FIS contains four components: fuzzification, fuzzy rule base, fuzzy inference engine and defuzzification [16].

\section{Fuzzification}

The fuzzification component builds fuzzy sets. By membership functions they form sets for input-output variables. Fuzzy membership functions may take many forms, but in practice there are two types of membership functions: triangular and bell-shaped (Gaussian). Facile implementation in the fuzzy toolbox of MATLAB provides a significant advantage for the triangular functions. The triangular membership functions were used in this study.

Membership functions to fuzzy variables may be assigned by intuition, rank ordering and inductive reasoning.

In this paper, the intuitive approach is used because of the simplicity and the fact that it derives from the innate intelligence and understanding of human beings.

\section{Fuzzy rule base}

The fuzzy rule base contains rules that include all possible fuzzy relations between inputs and outputs. These rules are expressed in the IF-THEN format. Generally, there are two types of rule systems, Sugeno (1985) and Mamdami (1977). Depending on the addressed problem, a user may choose the appropriate rule system. In this study, the Mamdanitype fuzzy rules were established. The following is an example for a Mamdani rule:

\section{IF binder content is high THEN strength is high}

The sequence "IF to THEN" of the fuzzy rule is named as 'the antecedent' part of the rule whilst the following is called as the consequent part. The Mamdani rule system both antecedent and consequent parts include verbal statements. Mamdani rules can be intuitively generated but also set-up based on the available data.

\section{Fuzzy inference engine}

The fuzzy inference engine considers entire set of fuzzy rules in the fuzzy rule base but also turns a set of inputs into corresponding outputs. In this respect, it runs either min or prod activation operators. The present study runs on the min method.

The next step within in the inferencing engine is named the composition. Here all of the fuzzy output subsets, got by the activation operators from the triggered rules, are combined each other in order to frame a single fuzzy subset allocated to the output variable. Targeting the scope, there are three main composition methods: maximization (max), summation (sum) and prober. The present study runs the max method.

Defuzzification

Defuzzification turns the fuzzy outputs from the fuzzy inference engine into a number. In practice there are many defuzzification methods. The most common are: center of gravity (centroid), bisector of area (bisector), middle of maximum (MOM), largest of maximum (lom), and smallest of maximum (som). The present study runs the centroid method which is also the defuzzification method most used in practice [17].

\section{Results and discussions}

The model's success in predicting the behaviour of polymer concrete mixtures depends on comprehensiveness of the training data.

To analyse the correlation between the mixture variables of polymer concrete and its measured properties, experimental data was required. The basic parameters considered in this study were epoxy resin (ER), silica fume (SUF), aggregate sort I (ASI) and aggregate sort II (ASII) dosage.

The polymer concrete was prepared with following components: epoxy resin as binding material, natural river aggregates in two sorts: $0-4 \mathrm{~mm}$ sort and $4-8 \mathrm{~mm}$ sort (with continuous granulometry) and silica fume as filler. The dosages of components and the complete list of data are presented in Table 1 [18]. The epoxy resin is a Romanian product named ROPOXID 701 that is combined with hardener, named ROMAMID 407. The polymer is produced by POLICOLOR S.A. Bucuresti. Silica fume is a by-product of producing ferrosilicon alloys from S.C. FERAL S.R.L. Tulcea, Romania. The properties of SUF are as follows: grey colour, spherical particle shape, specific surface 130,000 $\mathrm{m}^{2} / \mathrm{kg}$, density of $2,250 \mathrm{~kg} / \mathrm{m}^{3}$. The chemical composition of silica fume is represented by components such as: $\mathrm{SiO}_{2}$ in proportion of $91.7 \%, \mathrm{Fe}_{2} \mathrm{O}_{3}$ in proportion of $1.83 \%, \mathrm{Al}_{2} \mathrm{O}_{3}$ in proportion of $4.63 \%, \mathrm{CaO}$ in proportion of $0.5 \%$, etc. [19].

Each polymer concrete mixture (M1 - M15) was used for casting specimens that were evaluated under identical conditions, suitable to the procedures used in testing aggregate concrete under combined compression and shear stresses [20] and according to European Standard [21]. Because the main objective of this paper is to analyse the adhesion stresses (AS) by fuzzy method, the experimental responses at 14 days was experimentally determined as result of three tests. 
Table 1

MIXTURE DESIGN COMBINATIONS FOR PC

\begin{tabular}{|l|l|l|l|l|l|}
\hline Mixture & $\begin{array}{l}\text { ER } \\
(\%)\end{array}$ & $\begin{array}{l}\text { SUF } \\
(\%)\end{array}$ & $\begin{array}{l}\text { ASI } \\
(\%)\end{array}$ & $\begin{array}{l}\text { ASII } \\
(\%)\end{array}$ & $\begin{array}{l}\text { AS } \\
(\mathrm{MPa})\end{array}$ \\
\hline M1 & 18.80 & 6.40 & 37.40 & 37.40 & 7.27 \\
\hline M2 & 12.40 & 12.80 & 37.40 & 37.40 & 5.18 \\
\hline M3 & 12.40 & 6.40 & 43.80 & 37.40 & 5.67 \\
\hline M4 & 12.40 & 6.40 & 37.40 & 43.80 & 6.57 \\
\hline M5 & 15.60 & 9.60 & 37.40 & 37.40 & 8.45 \\
\hline M6 & 15.60 & 6.40 & 40.60 & 37.40 & 10.25 \\
\hline M7 & 15.60 & 6.40 & 37.40 & 40.60 & 9.01 \\
\hline M8 & 12.40 & 9.60 & 40.60 & 37.40 & 7.56 \\
\hline M9 & 12.40 & 9.60 & 37.40 & 40.60 & 7.66 \\
\hline M10 & 12.40 & 6.40 & 40.60 & 40.60 & 9.06 \\
\hline M11 & 16.40 & 7.20 & 38.20 & 38.20 & 5.87 \\
\hline M12 & 13.20 & 10.40 & 38.20 & 38.20 & 5.47 \\
\hline M13 & 13.20 & 7.20 & 41.40 & 38.20 & 5.77 \\
\hline M14 & 13.20 & 7.20 & 38.20 & 41.40 & 7.96 \\
\hline M15 & 14.00 & 8.00 & 39.00 & 39.00 & 10.15 \\
\hline & & & & & \\
\hline
\end{tabular}

\section{Fuzzy modeling}

As a system identification task, the fuzzy modeling runs two different phases: structure identification and parameter prediction.

Structure identification covers topics as selecting relevant input variables, choosing a specific type of FIS, determining the number of fuzzy rules, their antecedents and consequents and determining the type and number of membership functions.

Parameter prediction is determination of aimed values response to evident input values of constituted model.

The first step of structure identification is to determine the input and output variables. First of all, input variables with their membership functions are introduced. Second step is to describe the output variable with its membership function, [22].

$$
\text { -Input variables }
$$

In the present study the input variables are: ER content (\%), SUF content (\%) and ASI content (\%). Besides, there is a fourth component of the considered concrete, Aggregate Sort II (ASII), but this cannot be considered as independent variable because it is determined as a value as follows: $100-(\mathrm{ER}+\mathrm{SUF}+\mathrm{ASI})$.

-Output variable

In this paper, the output variable is Adhesion Stress (AS).

The limit values of input and output variables used in Mamdani-type fuzzy inference model are listed in Table 2.

Table 2

RANGE OF PARAMETERS

\begin{tabular}{|l|l|l|}
\hline Variable & Lower limit & Upper limit \\
\hline ER & 11 & 20 \\
\hline SUF & 5 & 14 \\
\hline ASI & 36 & 45 \\
\hline AS & 4.5 & 11 \\
\hline
\end{tabular}

Membership functions for input and output parameters used for fuzzy modelling are given in Fig. 1 - 4. The membership functions and the number of subsets were determined by considering the experimental data: the input variables ER, SUF and ASI have 8 fuzzy subsets whilst the output variable AS has 12 fuzzy subsets. 


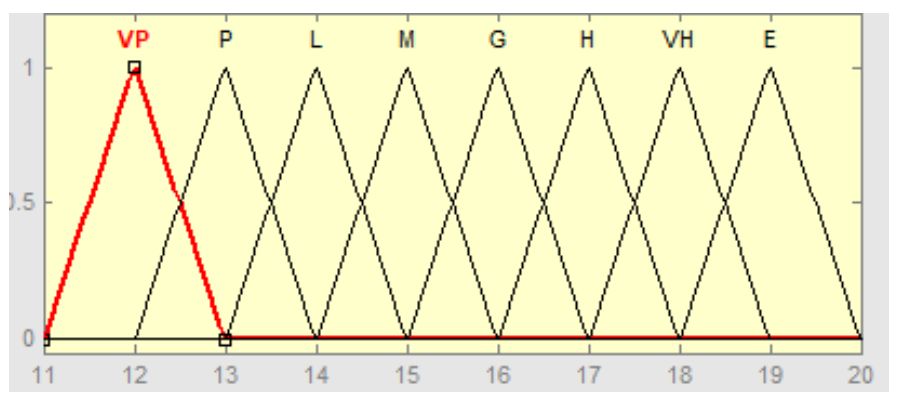

Fig. 1. Membership function for input data (ER)

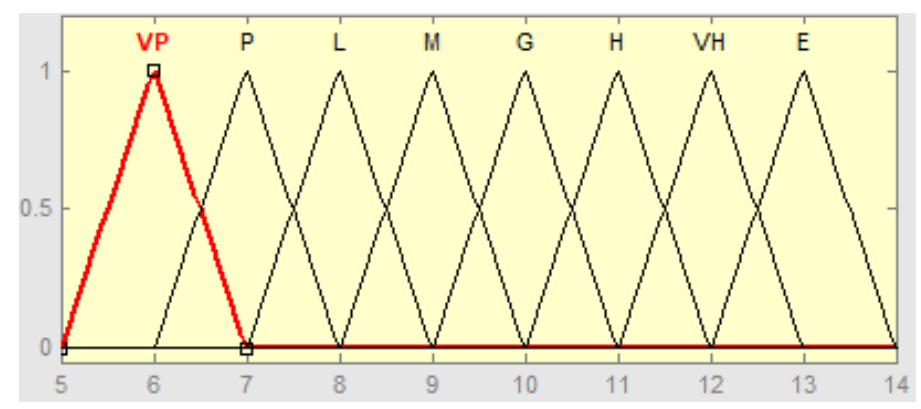

Fig. 2. Membership function for input data (SUF)

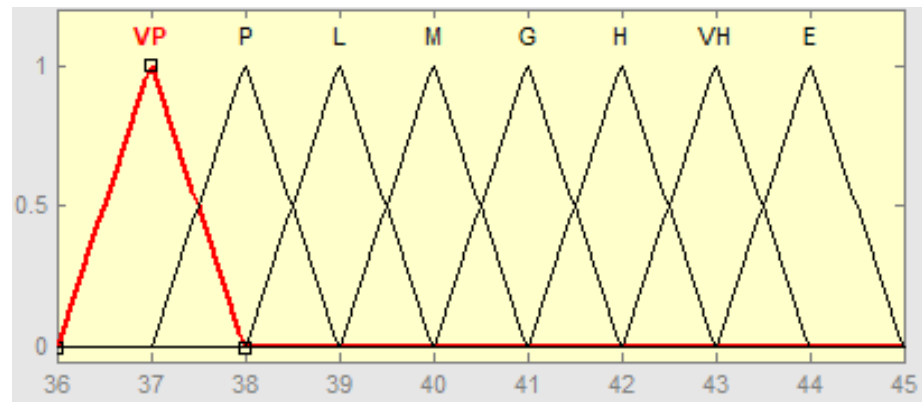

Fig. 3. Membership function for input data (ASI)

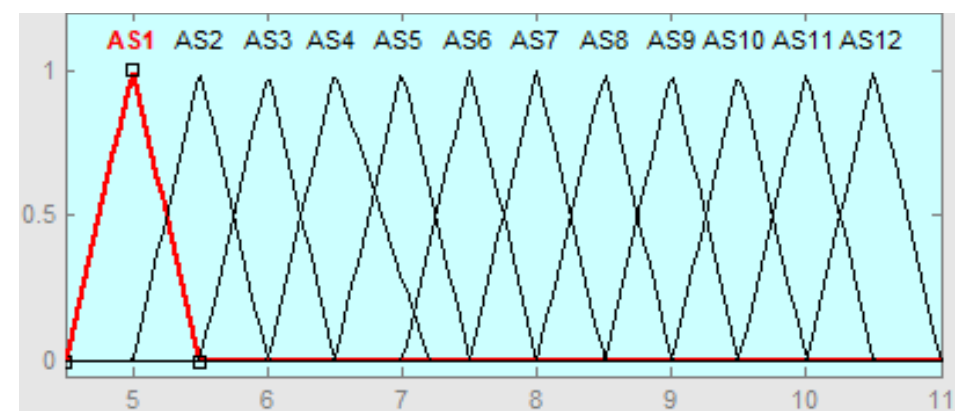

Fig. 4. Membership function for output data (AS)

-Fuzzy rule base

Rule base is the main part of FIS and the quality of results in fuzzy system depends on the fuzzy rules [23]. The Mamdani-type fuzzy rules were developed using the procedure outlined previously. Hypothetically, it is possible to generate $8 \times 8 \times 8 \times 12=6144$ fuzzy rules. In practice however, such a fuzzy model would not have been proper, efficient and friendly-user. Our FIS system includes 15 rules. The results with 15 rules are in line with the expert's idea and laboratory results.

-Fuzzification and defuzzification

The FIS system uses AND logical combination of inputs in the rules. The FIS system has following properties as can be seen in Fig. 5: 


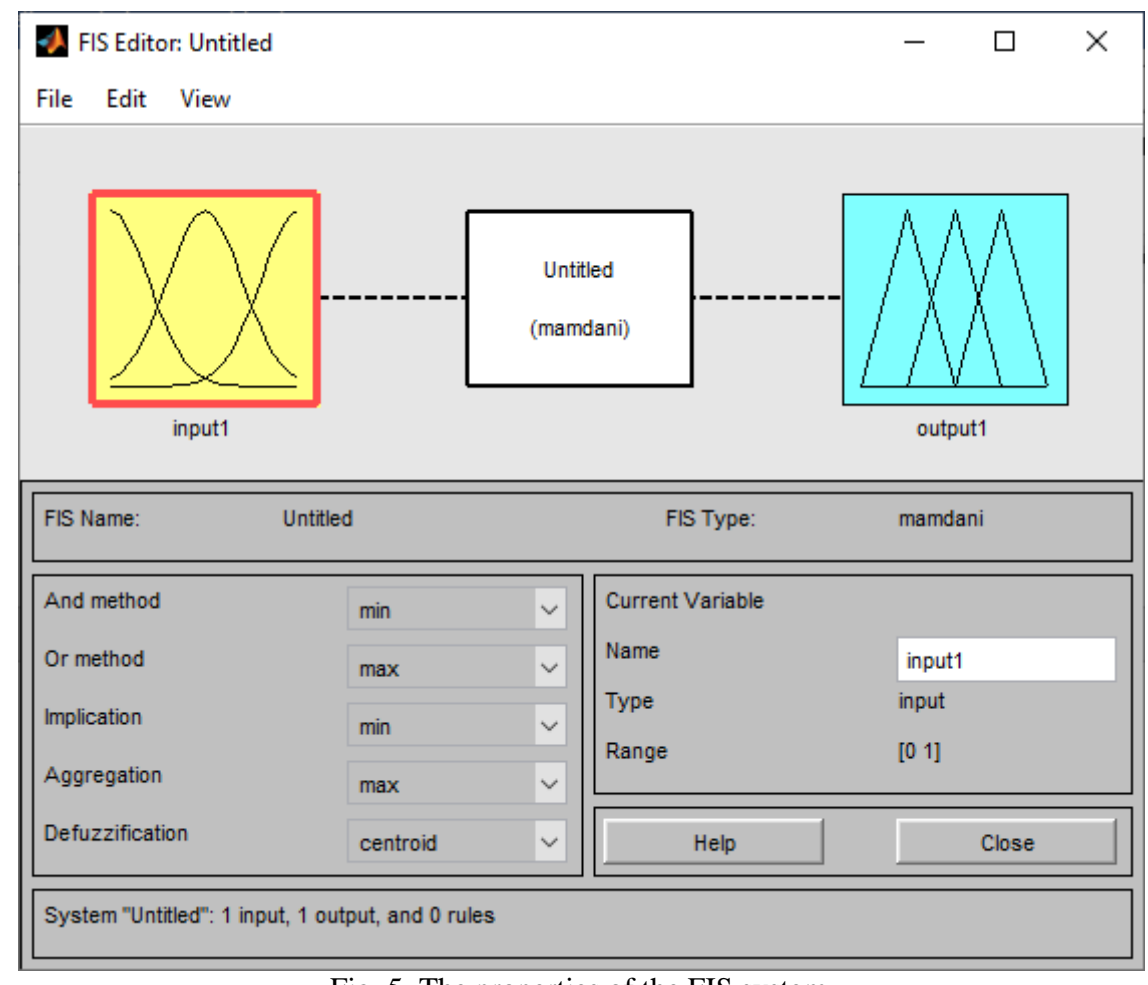

Fig. 5. The properties of the FIS system

At the end of the modeling process, the crisp results of the model are seen on the defuzzification screen (Fig. 6).

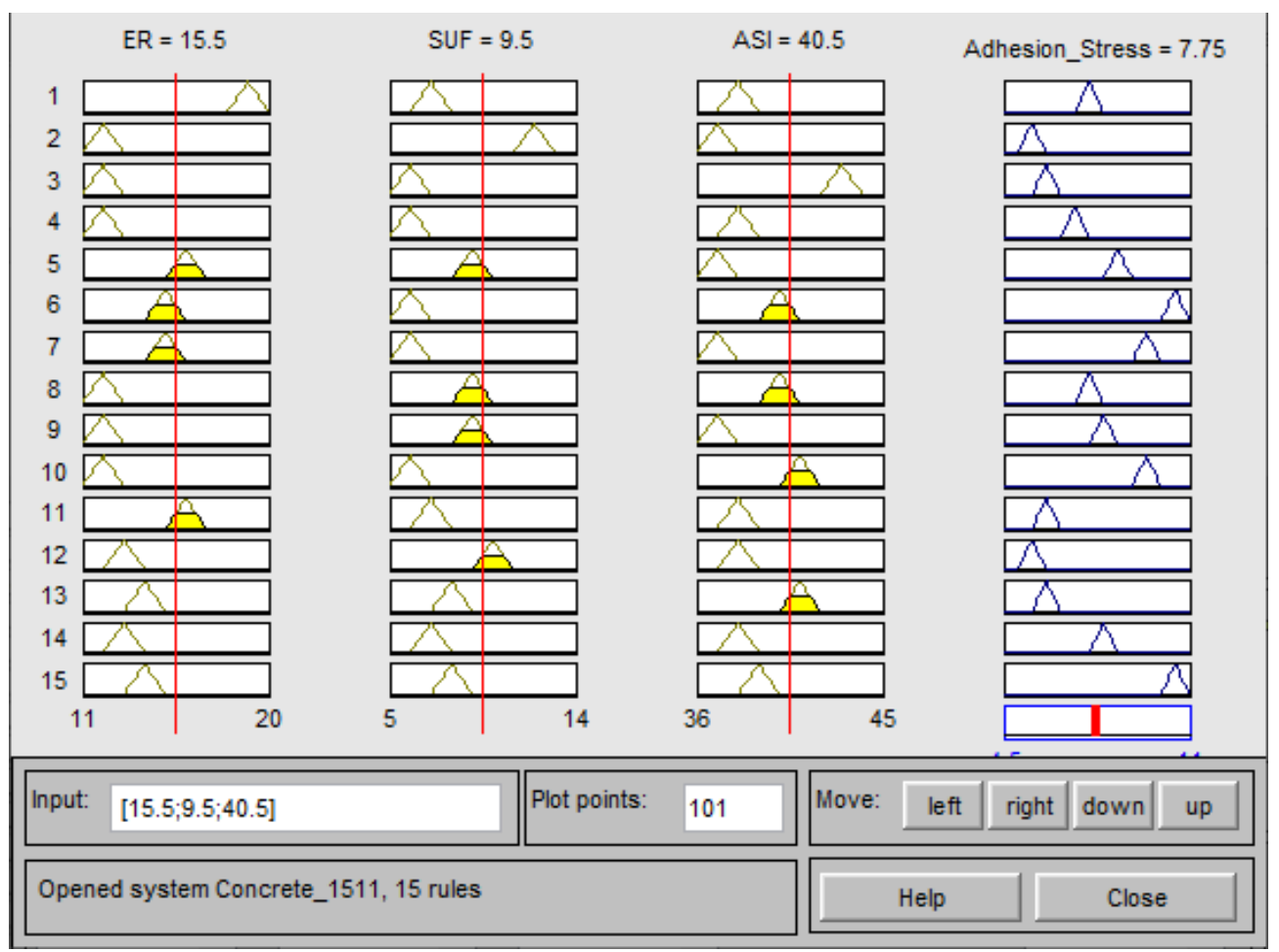

Fig. 6. Defuzzification aspect of the model

The surface viewer of some fields of our FIS system are shown in Figures 7-9. The fuzzy logic-based algorithm model was devised by using the fuzzy logic toolbox in MATLAB. 


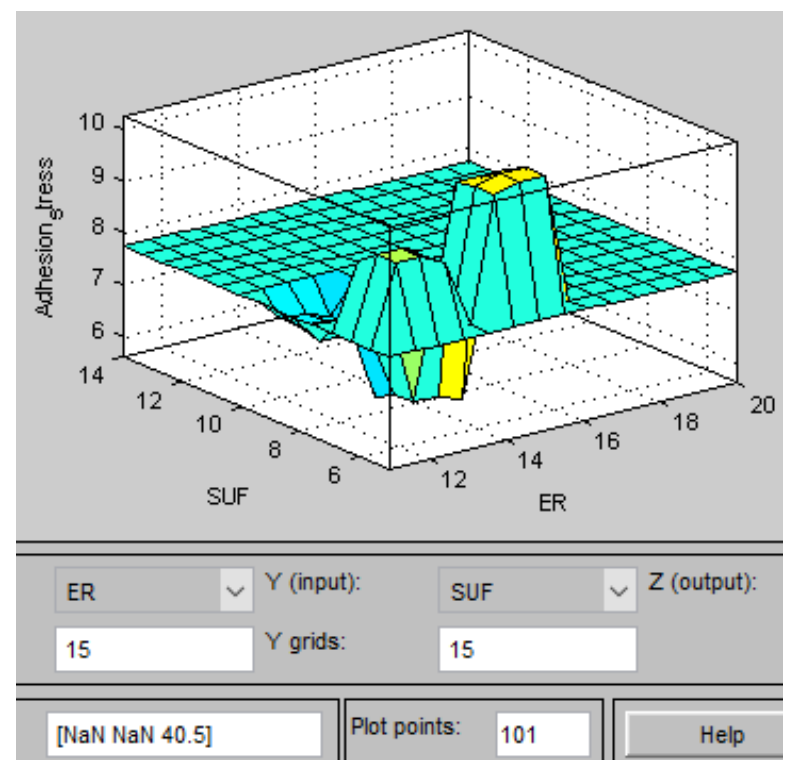

Fig. 7. Surface diagram for ER and SUF (inputs)

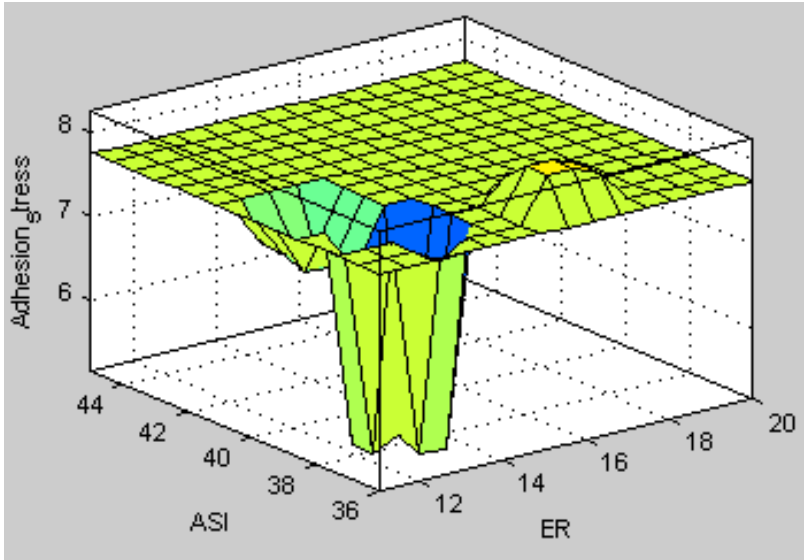

\begin{tabular}{|l|l|l|l|}
\hline \hline ER & $\checkmark$ (input): & ASI & $\checkmark$ (output): \\
\hline 15 & Y grids: & 15 & \\
\hline \hline [NaN 9.5 NaN] & & Plot points: 101 & Help \\
\hline
\end{tabular}

Fig. 8. Surface diagram for ER and ASI (inputs)

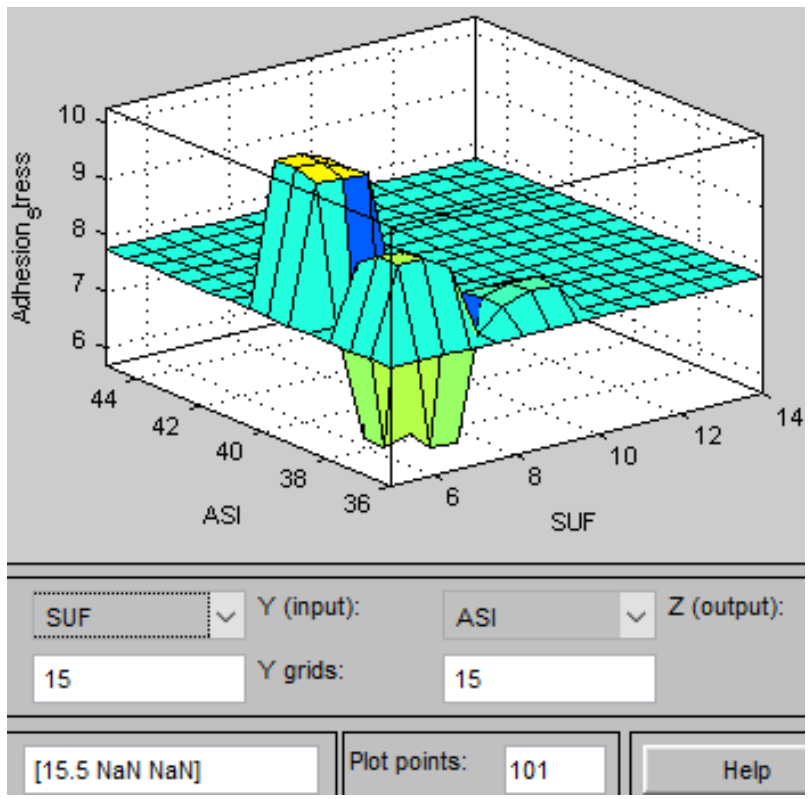

Fig. 9. Surface diagram for SUF and ASI (inputs) 
To evaluate the expected accuracy of fuzzy logic model there were calculated the root-mean-square error (RMSE), absolute fraction of variation (R2), mean absolute percentage error (MAPE) and mean prediction ratio (MPR), through the following equations:

where

$$
\begin{aligned}
& R M S E=\sqrt{\frac{1}{N} \sum_{i=1}^{N}\left|a_{i}-p_{i}\right|^{2}} \\
& R^{2}=1-\left(\frac{\sum_{i=1}^{N}\left(a_{i}-p_{i}\right)^{2}}{\sum_{i=1}^{N}\left(p_{i}\right)^{2}}\right) \\
& M A P E=\frac{1}{N} \sqrt{\left|\frac{\left(a_{i}-p_{i}\right)}{p_{i}}\right|} \cdot 100 \\
& M P R=\frac{1}{N} \sum_{i=1}^{N}\left(\frac{p_{i}}{a_{i}}\right)
\end{aligned}
$$

$a_{i}$ is the actual adhesion stress,

$p_{i}$ is the predicted value and $N$ is total sample number.

All of the statistical parameters prove that fuzzy logic model has the best accuracy of all and can predict adhesion stress very close to experiment results. Table 3 shows RMSE, R2, MAPE and MPR values.

Table 3

ERROR ANALYSES OF PREDICTION METHOD

\begin{tabular}{|l|l|}
\hline Errors name & Values obtained \\
\hline RMSE & 0.161 \\
\hline R2 & 0.996 \\
\hline MAPE & 1.708 \\
\hline MPR & 0.995 \\
\hline
\end{tabular}

Histogram diagram was created to show the relationship between the fuzzy logic model and the experimental results. The diagram is presented in Fig. 10.

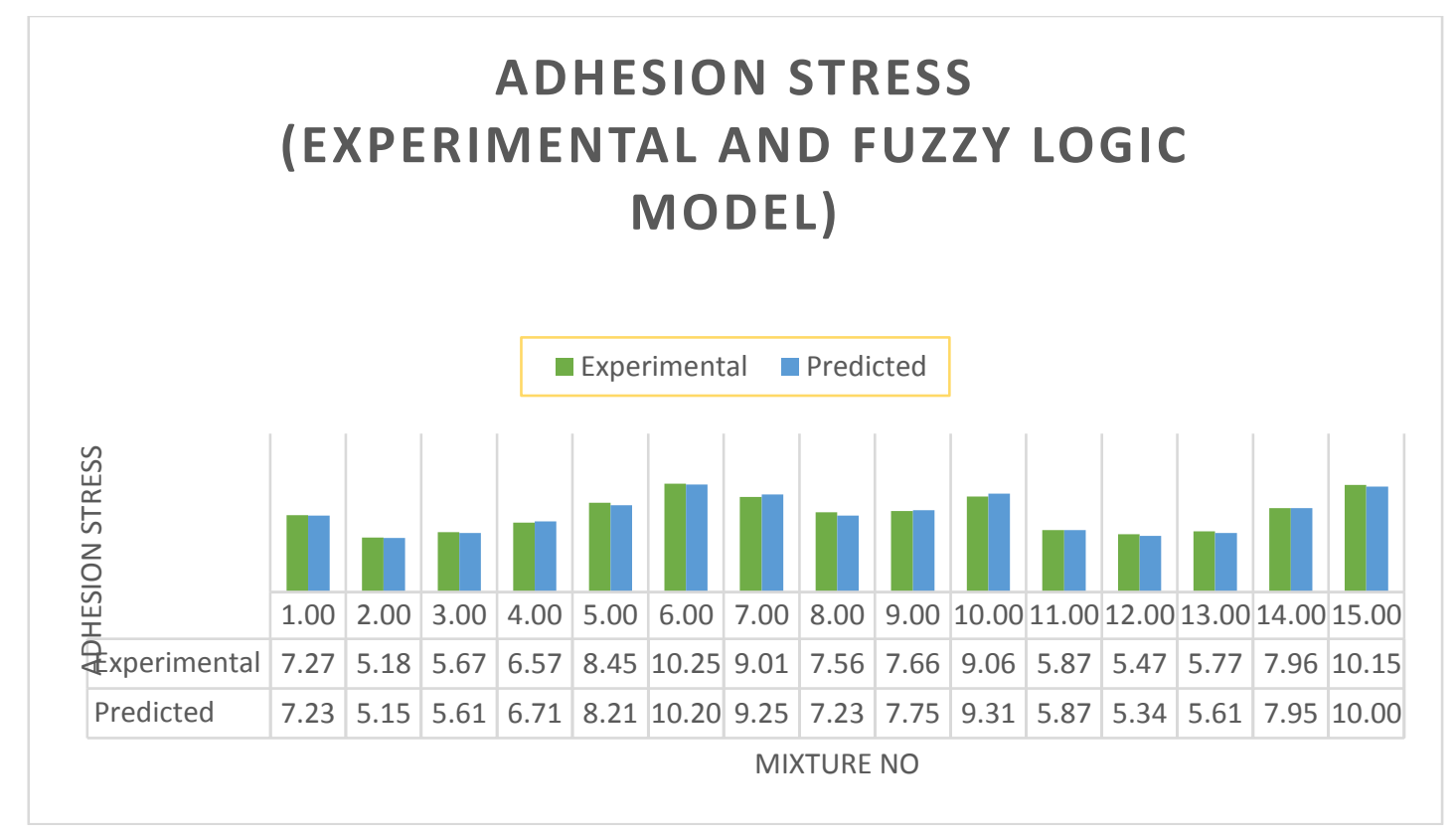

Fig. 10. Comparison of experimental and predicted values of adhesion stress results

Fig. 10 and Table 3 prove virtually perfect agreement of predicted values of the adhesion stress with the experimental ones.

\section{Conclusions}

In this study the proposed approach is made to apply the fuzzy logic in predicting of adhesion stress. The advantage of this method is that a lot of values for adhesion stress can be obtained without using lengthy formulations, experiments that require long-time involving much wastage of material and cost of concrete production [24]. The predicted results show good agreement with the experimental data. 
Figures 7, 8 and 9 helped identifying the mixtures which have advantageous values of adhesion stress, identifying which mixtures should be avoided because of the low values of adhesion stress. By analyzing the surface diagrams, we could identify highly sensitive areas in which $0.1-1.0 \%$ increase of a variable can produce a spectacular increase or decrease of adhesion stress. For example, in Figure 7 the ASI variable was fixed at $40.5 \%$ and we can see that the best values for adhesion stress correspond to the variable ER between 14 and 16 and SUF between 6 and 7. In Figure 8, for a fixed SUF variable at 9.5 we can see that the lowest values of adhesion stress are for ASI values between 37.4 and 38 and ER values between 12 and 14. In the same figure, the maximum values of adhesion stress are produced by ER values of 15 to 17. In Figure 9 the ER values are fixed at 15.5 with lowest adhesion stress values determined by ASI between 37.6 and 39, SUF between 6.4 and 8. Also, by increasing ASI values with $0.1-1 \%$, the values of AS were doubled, thus identifying the optimum mixture.

Further research is required to obtain a better understanding of FIS models. Other parameters like compressive strength, flexural strength, splitting tensile strength and density will be the focus of future research.

The results of this study provide helpful information for civil engineers and structural designers whilst this methodology can be used as a new tool to support the decision-making process in the concrete construction industry as a function of mixed proportions.

In the near future we intend to extend the simulation technique and calculation [ 26,27$]$ for estimation of other important quantities (material properties, in particular) in the process discussed, so that we have an integrative vision on the behavior of polymer concrete mixtures in operation, under conditions of high temperature and humidity.

\section{References}

1. BLAGA, A., BEAUDOIN, J.J., Polymer Concrete. Canadian Building Digest, Otawwa, 1985.

2. FOWLER, D.W., Cem. Concr. Composite, 21, 1999, p. 449-452.

3. FERDOUS, A., MANALO, A., ARAVINTHAN, T., VAN ERP, G., Construction and Building Materials, 127, 2016 , p. 539-545.

4. AGGARWAL, L.K., THAPLIYAL, P.C., KARADE, S.R., Constr. Build. Mater, 21, 2007, p. $379-383$.

5. GORNINSKI, J.P., DAL MOLIN, D.C., KAZMIERCZAK C.S., Construction and Building Materials, 21, 2007, p. 546-555.

6. LOKUGE, W., ARAVINTHAN, T., Materials\& Design, 51, 2013, p. 175-181.

7. BARBUTA, M., TIMU, A., BEJAN, L., et al., Mechanical Properties of Fly Ash Polymer Concrete with Different Fibers, Materiale Plastice, 55, no. 3, 2018, p. 405-409.

8. GOLESTANEH, M., AMINI, G., NAJAFPOUR, D., BEYGI, M.A., World Appl Sci J, 9, 2010 , p. $216-220$.

9. MARTINEZ-BARRERA, G., MENCHACA-CAMPOS, C., GENCEL, O., Constr. Build. Mater, 41, 2013, p. 204-208.

10. BARBUTA, M., HARJA, M., CIOBANU, G., Agriculture and Environment, 12, no. 2, 2014, p. 1185-1190.

11. NA, U.J., PARK, T.W., FENG, M.Q. and CHUNG, L., Magazine of Concrete Research, 61, 2009 , p. $245-256$.

12. ZADEH, L.A., Information and Control, 8, 1965, p. $338-353$.

13. DEMIR, F., Cement and Concrete Research, 35, 2005, p. 1531-1538.

14. MAMDANI, E.H. and ASSILIAN, S., International Journal of Man-Machine Studies, 7, 1975 , p. 1-13.

15. McNEILL, F.M., Application of Fuzzy Logic in Interior Daylight Estimation. Thro, E. Fuzzy Logic: A Practical Approach. AP Professional, Boston MA, 1994.

16. INAN, G, GOKTEPE, A.B., RAMYAR, K. and SEZER, A., Building and Environment, 42, 2007, p. 1264-1269.

17. TAYFUR, G., TAHIR, K., ERDEM, T.K. and KIRCA, Ö., J. Mater. Civ. Eng., 26, no. 11, 2014, p. 04014079-1-04014079-7.

18. BARBUTA, M., LEPADATU, D., PATRAS, B.M., Mixture Design of Experiment for Multicriterial Optimization of Polymer Concrete. International ScientificConference 2008; VSU: VI-1 - VI-6, 2008.

19. BARBUTA, M., HARJA, M., Polymer concrete. Editura Politehnium, Iasi, 2009.

20. BEJAN, L., SIRBU, A., TARANU, N., Mat. Plast., 44, no. 1, 2007, p. 22-25.

21. EN 12390/2001, Testing hardened concrete. European Committee for Standardization, Brussels, 2001.

22. NESHAT, M., ADELI, A., SEPIDNAM, G. and SARGOLZAEI, M., International Journal of the Physical Sciences, 7, no. 3, 2012, p. 440 455 .

23. NIKRAVESH, M., ZADEH, L.A., (Eds), Forging New Frontier: Fuzzy Pioneer I. Hardcover, ISBN 978-3-540-73181-8, 2007.

24. NAZARI, A. AND G. KHALAJ, G., Mat. Res., 15, no. 2, 2012, p. 242-252.

25. ÜNAL, O., DEMIR, F., UYGUNOĞLU, T., Building and Environment, 42, no. 10, 2007, p. 3589-3595.

26. PAUN, V.P., Mat. Plast., 44, no. 4, 2007, p. 393-395.

27. PAUN, V.P., Mat. Plast.. 43, no.1, 2006, p. 57-58.

Manuscript received: 30.10 .2019 